\title{
Synthesis and Characterization of Benzimidazolium Salts Bearing Triazole Groups
}

\author{
Deniz Demir Atlı \\ Manisa Celal Bayar University, Faculty of Science and Letters, 45140, Manisa, Turkey, \\ Phone: +902362013177 \\ deniz.demir@cbu.edu.tr
}

Received: 25 October 2017

Accepted: 15 February 2018

DOI: $10.18466 /$ cbayarfbe. 346566

\begin{abstract}
A propargyl-functionalized salt, 1-(2-methoxyethyl)-3-(prop-2-ynyl)benzimidazolium bromide (1), was prepared. 1-(2-methoxyethyl)-3-[(1-phenyl-1H-1,2,3-triazol-4-yl)methyl]benzimidazolium hexafluorophosphate (2) and 1-(2-methoxyethyl)-3-[(1-(4-nitrophenyl)-1H-1,2,3-triazol-4-yl)methyl]benzimidazolium hexafluorophosphate $(3)$ were obtained by $\mathrm{Cu}(\mathrm{I})$ catalyzed azide-alkyne cycloaddition reaction of 1 with corresponding azides. Compound 3 was transformed to 1-(2-methoxyethyl)-3-[(1-(4-aminophenyl)-1H-1,2,3triazol-4-yl)methyl]benzimidazolium hexafluorophosphate (4) by reduction reaction with hydrazine monohydrate. The structures of these propargyl- and 1,2,3-triazolyl-functionalized benzimidazolium salts were elucidated by FT-IR, ${ }^{1} \mathrm{H}$ NMR, ${ }^{13} \mathrm{C}$ NMR and elemental analysis methods.

Keywords: Benzimidazolium, N-heterocyclic carbene, Click chemistry, triazole
\end{abstract}

\section{Introduction}

Preparation of the first free and stable N-heterocyclic carbene (NHC) was reported in 1991 [1]. NHCs, strong $\sigma$-donors and weak $\pi$-acceptors, compose NHC-metal complexes stable towards air, moisture and heat. NHC-metal complexes have received excessive attention because of wide applications in homogeneous catalysis. 1,2,3-triazoles are biologically active compounds and so they have been extensively used [2-7]. Although 1,2,3triazole heterocycle has been known since the end of the $19^{\text {th }}$ century, triazole chemistry has become popular by presenting "Click chemistry" concept by Sharpless' group in 2001 [8]. 1,3-cycloaddition reaction of an alkyne with an azide catalyzed by copper(I) gives 1,4-disubstituted 1,2,3-triazole without byproducts under moderate conditions and in short times (Figure 1). This method has been widely used for synthesizing several ligands comprising 1,4-disubstituted 1,2,3-triazolyl groups [9-14]. The metal complexes of these ligands have drawn attention because of their catalytic activities in many organic transformations [15-18].

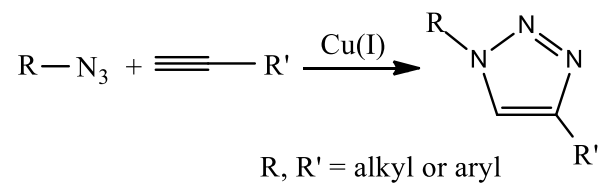

Figure 1. Copper(I) catalyzed 1,3-cycloaddition reaction
There have been limited number of reports regarding bidentate NHC ligands bearing 1,2,3-triazolyl groups and metal complexes. Firstly, Pd(II) complexes were reported by Warsink et al. in 2010 [19]. They exhibit activities in the transfer semihydrogenation of alkynes to Z-alkenes. In another study, cationic rodium and iridium complexes were prepared [20]. $\mathrm{Gu}$ et al. synthesized palladium, platinum and copper complexes [21,22]. It was reported that palladium and copper complexes showed high activities in Suzuki-Miyaura cross coupling and azidealkyne cycloaddition reactions, respectively.

In this paper, preparation of a propargyl benzimidazolium salt and three 1,2,3-triazolylfunctionalized benzimidazolium compounds are reported. The structures of the synthesized compounds are defined by FT-IR, ${ }^{1} \mathrm{H}$ NMR, ${ }^{13} \mathrm{C}$ NMR and elemental analysis methods.

\section{Materials and Methods \\ 2.1. General Considerations}

All experiments were achieved under air. The reagents and organic solvents were used as purchased. 1-(2-methoxyethyl)benzimidazole, p-nitrophenyl azide and phenyl azide were prepared as reported procedures $[23,24]$. Elemental analysis measures were achieved on a CHNS-932 (LECO) elemental analyzer. Varian 400 $\mathrm{MHz}$ NMR spectrophotometer was used for ${ }^{1} \mathrm{H}$ and ${ }^{13} \mathrm{C}$ NMR. FT-IR spectra were monitored on Perkin Elmer spectrophotometer at $400-4000 \mathrm{~cm}^{-1}$. Melting points 
were measured in glass capillary tubes under air with Electrothermal 9100 apparatus.

2.2. Synthesis of 1-(2-methoxyethyl)-3-(prop-2ynyl)benzimidazolium bromide (1)

Propargyl bromide $(2.20 \mathrm{~mL}, 20.24 \mathrm{mmol}, 80 \mathrm{wt} \%$ toluene solution) was added to the solution of 1-(2-methoxyethyl)benzimidazole (1.43 g, $8.10 \mathrm{mmol})$ in $\mathrm{CH}_{3} \mathrm{CN}(20 \mathrm{~mL})$. The mixture was refluxed overnight. The solvent was removed. The crude was washed with $\mathrm{Et}_{2} \mathrm{O}(3 \times 5 \mathrm{~mL})$. The product was recrystallized from EtOH. Yield: 1.58 g, 66\%. mp: $149-150{ }^{\circ} \mathrm{C} .{ }^{1} \mathrm{H}$ NMR (400MHz, DMSO-d6): $\delta=9.86$ (s, 1H, NCHN), 8.14$8.02(\mathrm{~m}, 2 \mathrm{H}, \mathrm{Ar}-\mathrm{H}), 7.75-7.68(\mathrm{~m}, 2 \mathrm{H}, \mathrm{Ar}-\mathrm{H}), 5.56(\mathrm{~d}$, $\left.2 \mathrm{H}, \mathrm{J}=2.35 \mathrm{~Hz}, \mathrm{CH}_{2} \mathrm{C}=\mathrm{CH}\right), 4.75-4.72(\mathrm{~m}, 2 \mathrm{H}$, $\mathrm{CH}_{2} \mathrm{CH}_{2} \mathrm{OCH}_{3}$ ), 3.85 (t, $\left.1 \mathrm{H}, \mathrm{J}=2.54 \mathrm{~Hz}, \mathrm{C} \equiv \mathrm{CH}\right), 3.79$ $3.77\left(\mathrm{~m}, \quad 2 \mathrm{H}, \quad \mathrm{CH}_{2} \mathrm{CH}_{2} \mathrm{OCH}_{3}\right), \quad 3.25 \quad(\mathrm{~s}, \quad 3 \mathrm{H}$, $\mathrm{CH}_{2} \mathrm{CH}_{2} \mathrm{OCH}_{3}$ ) ppm. ${ }^{13} \mathrm{C}$ NMR (100MHz, DMSO-d6): $\delta=142.83,131.81,130.76,127.32,127.27,114.66$, 114.23, 79.67, 76.06, 69.51, 58.66, 47.23, 37.23 ppm. FT-IR $(\mathrm{KBr}) v_{(\mathrm{C} \equiv \mathrm{C})}: 2124 \mathrm{~cm}^{-1}, v_{(\mathrm{NCN})}: 1566 \mathrm{~cm}^{-1}$. Anal. Calc. for $\mathrm{C}_{13} \mathrm{H}_{15} \mathrm{~N}_{2} \mathrm{OBr}$ : C, 52.89; H, 5.13; N 9.49\%. Found: C, 52.15; H, 4.86; N, 9.34\%.

2.3. Synthesis of 1-(2-methoxyethyl)-3-[(1-phenyl-1H1,2,3-triazol-4-yl)methyl]benzimidazolium hexafluorophosphate (2)

A mixture of phenyl azide $(0.14 \mathrm{~g}, 1.2 \mathrm{mmol})$, 1 (0.30 g, $1 \mathrm{mmol})$, sodium L-ascorbate $(0.02 \mathrm{~g}, 0.1$ mmol) and $\mathrm{CuSO}_{4} \cdot 5 \mathrm{H}_{2} \mathrm{O}(0.012 \mathrm{~g}, 0.05 \mathrm{mmol})$ was stirred in tert-butyl alcohol and water $(6 \mathrm{~mL}, 1 / 1)$ for $24 \mathrm{~h}$ at $50{ }^{\circ} \mathrm{C}$. After filtration, a methanolic solution of $\mathrm{NH}_{4} \mathrm{PF}_{6}(0.20 \mathrm{~g}, 1.2 \mathrm{mmol})$ was added to the filtrate. The mixture was stirred for $2 \mathrm{~h}$ at room temperature. Water $(10 \mathrm{~mL})$ was added to the solution. The powder pink solid was collected by filtration and washed with water $(2 \times 5 \mathrm{~mL})$. The product was recrystallized from $\mathrm{CH}_{2} \mathrm{Cl}_{2} / \mathrm{Et}_{2} \mathrm{O}$. Yield: $0.48 \mathrm{~g}, 62 \%$. mp: $142-143{ }^{\circ} \mathrm{C}$. ${ }^{1} \mathrm{H}$ NMR (400MHz, DMSO-d6): $\delta=9.88$ (s, 1H, NCHN), 8.98 (s, 1H, triazole), 8.15-8.07 (m, 2H, Ar-H), 7.86$7.83(\mathrm{~m}, 2 \mathrm{H}, \mathrm{Ar}-\mathrm{H}), 7.72-7.67(\mathrm{~m}, 2 \mathrm{H}, \mathrm{Ar}-\mathrm{H}), 7.60(\mathrm{t}, 2 \mathrm{H}$, $\mathrm{J}=7.83 \mathrm{~Hz}, \mathrm{Ar}-\mathrm{H}), 7.52-7.48(\mathrm{~m}, 1 \mathrm{H}, \mathrm{Ar}-\mathrm{H}), 6.00(\mathrm{~s}, 2 \mathrm{H}$, $\left.\mathrm{CH}_{2}\right), 4.73\left(\mathrm{t}, 2 \mathrm{H}, \mathrm{J}=4.70 \mathrm{~Hz}, \mathrm{CH}_{2} \underline{\mathrm{CH}}_{2} \mathrm{OCH}_{3}\right), 3.80(\mathrm{t}$, $\left.2 \mathrm{H}, \quad \mathrm{J}=4.89 \mathrm{~Hz}, \quad \underline{\mathrm{CH}}_{2} \mathrm{CH}_{2} \mathrm{OCH}_{3}\right), 3.26(\mathrm{~s}, \quad 3 \mathrm{H}$, $\mathrm{CH}_{2} \mathrm{CH}_{2} \mathrm{OCH}_{3}$ ) ppm. ${ }^{13} \mathrm{C}$ NMR (400MHz, DMSO-d6): $\delta=143.22,141.49,136.77,131.82,131.23,130.43$, 129.52, 127.23, 127.20, 123.59, 120.70, 114.47, 114.38, 69.50, 58.64, 47.21, 42.13 ppm. FT-IR (KBr): $v_{(\mathrm{NCN})}$ : $1563 \mathrm{~cm}^{-1}$. Anal. Calc. for $\mathrm{C}_{19} \mathrm{H}_{20} \mathrm{~N}_{5} \mathrm{OPF}_{6}: \mathrm{C}, 47.60 ; \mathrm{H}$, 4.21 ; N 14.61\%. Found: C, 47.23; H, 4.27; N, $14.55 \%$.

2.4. Synthesis of 1-(2-methoxyethyl)-3-[(1-(4nitrophenyl)-1H-1,2,3-triazol-4-yl)methyl]benzimidazolium hexafluorophosphate (3)

A mixture of p-nitrophenyl azide $(0.20 \mathrm{~g}, 1.2 \mathrm{mmol}), \mathbf{1}$ $(0.30 \mathrm{~g}, 1 \mathrm{mmol})$, sodium L-ascorbate $(0.020 \mathrm{~g}, 0.1$ $\mathrm{mmol})$ and $\mathrm{CuSO}_{4} \cdot 5 \mathrm{H}_{2} \mathrm{O}(0.012 \mathrm{~g}, 0.05 \mathrm{mmol})$ was stirred in tert-butyl alcohol and water $(6 \mathrm{~mL}, 1 / 1)$ for $24 \mathrm{~h}$ at $50{ }^{\circ} \mathrm{C}$. Water $(20 \mathrm{~mL})$ was added to the mixture. After filtration, an aqueous solution of $\mathrm{NH}_{4} \mathrm{PF}_{6}(0.20 \mathrm{~g}, 1.2$ $\mathrm{mmol}$ ) was added to the filtrate. The resulting suspension was stirred for $2 \mathrm{~h}$ at room temperature. The yellow precipitate was collected by filtration and washed with water $(2 \times 5 \mathrm{~mL})$. The product was recrystallized from $\mathrm{CH}_{2} \mathrm{Cl}_{2} / \mathrm{Et}_{2} \mathrm{O}$. Yield: 0.41 g, 79\%. mp: $150-151{ }^{\circ} \mathrm{C}$. ${ }^{1} \mathrm{H}$ NMR (400MHz, DMSO-d6): $\delta=9.89$ (s, 1H, NCHN), 9.18 (s, $1 \mathrm{H}$, triazole), 8.47-8.43 (m, 2H, Ar-H ), 8.19-8.16 (m, 2H, Ar-H), 8.14-8.09 (m, 2H, Ar-H), 7.72-7.68 (m, $2 \mathrm{H}, \mathrm{Ar}-\mathrm{H}), 6.03\left(\mathrm{~s}, 2 \mathrm{H}, \mathrm{CH}_{2}\right), 4.74-4.72(\mathrm{~m}, 2 \mathrm{H}$, $\left.\mathrm{CH}_{2} \mathrm{CH}_{2} \mathrm{OCH}_{3}\right), 3.81-3.79\left(\mathrm{~m}, 2 \mathrm{H}, \underline{\mathrm{CH}_{2}} \mathrm{CH}_{2} \mathrm{OCH}_{3}\right), 3.26$ (s, 3H, $\left.\mathrm{CH}_{2} \mathrm{CH}_{2} \mathrm{OCH}_{3}\right)$ ppm. ${ }^{13} \mathrm{C}$ NMR (100MHz, DMSO-d6): $\delta=147.41,143.27,142.10,140.97,131.80$, 131.22, 127.26, 127.23, 126.08, 124.10, 121.31, 114.49, $114.38,69.50,58.65,47.24,42.02$ ppm. FT-IR(KBr) $v_{(\mathrm{NCN})}: 1569 \mathrm{~cm}^{-1}, v_{(\mathrm{NO})}: 1526$ and $1340 \mathrm{~cm}^{-1}$. Anal. Calc. for $\mathrm{C}_{19} \mathrm{H}_{19} \mathrm{~N}_{6} \mathrm{O}_{3} \mathrm{PF}_{6}: \mathrm{C}, 43.52 ; \mathrm{H}, 3.66 ; \mathrm{N} 16.03 \%$. Found: C, 44.05; H, 3.68; N, 16.19\%.

2.5. Synthesis of 1-(2-methoxyethyl)-3-[(1-(4aminophenyl)-1H-1,2,3-triazol-4-yl)methyl]benzimidazolium hexafluorophosphate (4)

Hydrazine monohydrate $(3.0 \mathrm{~mL}$, excess) and palladium on carbon $(10 \%(\mathrm{w} / \mathrm{w}), 0.015 \mathrm{~g})$ were added to the solution of $\mathbf{3}(0.78 \mathrm{~g}, 1.44 \mathrm{mmol})$ in $\mathrm{MeOH}(30 \mathrm{~mL})$ and THF (15 mL). The mixture was refluxed overnight and cooled to the room temperature. THF $(30 \mathrm{~mL})$ was added. The mixture was filtrated and rinsed with THF $(3 \times 15$ $\mathrm{mL}$ ). After removing of the solvent, the product was washed with $\mathrm{Et}_{2} \mathrm{O}(3 \times 10 \mathrm{~mL})$. It was recystallized from $\mathrm{MeOH} / \mathrm{Et}_{2} \mathrm{O}(1 / 3)$ at room temperature. Yield: $0.50 \mathrm{~g}$, 71\%. mp: $188-189{ }^{\circ} \mathrm{C}$. ${ }^{1} \mathrm{H}$ NMR (400MHz, DMSO-d6): $\delta=9.85(\mathrm{~s}, 1 \mathrm{H}, \mathrm{NCHN}), 8.69(\mathrm{~s}, 1 \mathrm{H}$, triazole $), 8.12-8.06$ $(\mathrm{m}, 2 \mathrm{H}, \quad$ Ar-H), 7.71-7.66 (m, 2H, Ar-H), 7.43-7.40 (m, 2H, Ar-H), 6.67-6.63 (m, 2H, Ar-H), 5.92 (s, 2H, $\mathrm{CH}_{2}$ ), $5.53\left(\mathrm{~s}, 2 \mathrm{H}, \mathrm{NH}_{2}\right), 4.72-4.69\left(\mathrm{~m}, 2 \mathrm{H}, \mathrm{CH}_{2} \mathrm{CH}_{2} \mathrm{OCH}_{3}\right)$, 3.79-3.76 (m, 2H, $\left.\underline{\mathrm{CH}_{2}} \mathrm{CH}_{2} \mathrm{OCH}_{3}\right), 3.24(\mathrm{~s}, 3 \mathrm{H}$, $\mathrm{CH}_{2} \mathrm{CH}_{2} \mathrm{OCH}_{3}$ ) ppm. ${ }^{13} \mathrm{C} \mathrm{NMR}(100 \mathrm{MHz}$, DMSO-d6): $\delta$ $=150.12,143.16,140.85,131.81,131.20,127.20$, $127.17,125.93,123.00,122.17,114.47,114.40,114.22$, $69.51,58.65,47.18,42.20$ ppm. FT-IR $(\mathrm{KBr}) v_{(\mathrm{NH} 2)}: 3400$ and $3495 \mathrm{~cm}^{-1}, v_{(\mathrm{NCN})}$ : $1563 \mathrm{~cm}^{-1}$. Anal. Calc. for $\mathrm{C}_{19} \mathrm{H}_{21} \mathrm{~N}_{6} \mathrm{OPF}_{6}: \mathrm{C}, 46.15 ; \mathrm{H}, 4.29 ; \mathrm{N}, 17.00 \%$. Found: $\mathrm{C}$, $46.52 ; \mathrm{H}, 4.21 ; \mathrm{N}, 16.89 \%$.

\section{Results and Discussion}

The methods for synthesizing of the compounds 1-4 are given in Figure 2. 1 was prepared by refluxing of 1-(2-methoxyethyl)benzimidazole with propargyl bromide in acetonitrile. Copper(I) catalyzed alkyne-azide cycloaddition reaction of $\mathbf{1}$ with phenyl azide and p-nitrophenyl azide gave the benzimidazolium salts containing triazole groups, $\mathbf{2}$ and $\mathbf{3}$, respectively. In this reaction, $\mathrm{CuSO}_{4} \cdot 5 \mathrm{H}_{2} \mathrm{O}$ and sodium L-ascorbate were employed as catalyst system. 2-3 were obtained as $\mathrm{PF}_{6}-$ salts by counter-anion exchange. The compound $\mathbf{4}$ was prepared by the reduction of $\mathbf{3}$ with hydrazine hydrate. 
<smiles>C#CC[n+]1cn(CCOC)c2ccc(C)cc21</smiles><smiles>[R]c1ccc(-n2cc(CN3CN(CC(C)C)c4ccccc43)nn2)cc1</smiles><smiles>COCn1c[n+](Cc2cn(-c3ccc(N)cc3)nn2)c2ccccc21</smiles>

Figure 2. Synthesis of the salts $\mathbf{1 - 4}$

FT-IR peaks at $1563-1569 \mathrm{~cm}^{-1}$ concern the stretching vibrations of $-\mathrm{C}=\mathrm{N}-$ groups for compounds 1-4. These values are consistent with the literature $[25,26] .1$ has a sharp band at around $2124 \mathrm{~cm}^{-1}$ assigned to $v(\mathrm{C} \equiv \mathrm{C})$ of the alkyne group. The extinction of this alkyne peak and the formation of the peaks appeared at $3150-3170 \mathrm{~cm}^{-1}$ related to the stretching frequencies of $\mathrm{C}-\mathrm{H}$ bond in the spectra of $\mathbf{2 - 4}$ confirm the formation of triazole groups. In the spectrum of $\mathbf{3}$ having nitro group, symmetric and asymmetric nitro stretching frequencies are observed at 1525 and $1339 \mathrm{~cm}^{-1}$. The peaks existing at 3490 and $3400 \mathrm{~cm}^{-1}$ in the spectrum of 4 relate to primer amine group.

NMR data confirm the suggested structures. In the ${ }^{1} \mathrm{H}$ NMR spectra of the all synthesized compounds, acidic NCHN proton resonances appear at 9.85-9.90 ppm. These resonance values are characteristic for NCHN protons of benzimidazolium salts $[25,26]$. For 1, terminal alkynyl proton is observed at $3.85 \mathrm{ppm}$ with a triplet signal. Singlet signals appeared at 8.98, 9.18 and 8.69 ppm in the ${ }^{1} \mathrm{H}$ NMR spectra of $\mathbf{2 - 4}$, respectively, show the formation of 1,2,3-triazole ring. ${ }^{13} \mathrm{C}$ NMR spectrum of 1 exhibits two signals at 79.67 and $76.06 \mathrm{ppm}$ for alkynyl carbons and a signal at $142.83 \mathrm{ppm}$ for NCN carbon. For the all compounds the signals attributed to aliphatic carbons of (2-methoxy)ethyl groups appear at almost the same values at $47-70 \mathrm{ppm}$. In the ${ }^{13} \mathrm{C}$ NMR spectra of 2-4, methylene carbons bound to 1,2,3-triazole ring are observed around $42 \mathrm{ppm}$.

\section{Conclusion}

Benzimidazolium salts bearing propargyl and triazole groups were prepared. The structures of the compounds were determined by spectroscopic methods and elemental analysis. Further studies on synthesizing of transition metal-NHC complexes of these NHC precursors are in progress.

\section{Acknowledgements}

This work was financially supported by Manisa Celal Bayar University Research Fund (MCBUBAP: 2015/192).

\section{References}

1. Arduendo, A.J, Harlow, R.L, Kline, M, A stable crystalline carbene, Journal of American Chemical Society, 1991, 113, 361363.

2. Marciniec, K, Latocha, M, Kurczab, R, Boryczka, S, Synthesis and anticancer activity evaluation of a quinoline-based 1,2,3-triazoles, Medicinal Chemistry Research, 2017, 26, 2432-2442.

3. Yadav, P, Lal, K, Rani, P, Mor, S, Kumar, A, Kumar, A, Efficient synthesis and antimicrobial evaluation of $2-((1$-substituted- $1 \mathrm{H}-$ 1,2,3-triazol-4-yl)-1-naphthaldehydes and their oxime derivatives, Medicinal Chemistry Research, 2017, 26, 1469-1480.

4. Subhashini, N.J.P, Sravanthi, K, Sravanthi, C, Reddy, M.S, Microwave-assisted synthesis of pyrazole-based 1,2,3-triazole derivatives and evaluation of their antimicrobial activity, Russian Journal of General Chemistry, 2016, 86, 2777-2784.

5. Ali, A.A, Gogoi, D, Chaliha, A.K, Burogohain, A.K, Trivedi, P, Saikia, P.J, Gehlot, P.S, Kumar, A, Chaturvedi, V, Sarma, D, Synthesis and biological evaluation of novel 1,2,3-triazole derivatives as anti-tubercular agents, Bioorganic\&Medicinal Chemistry Letters, 2017, 27, 3698-3703.

6. Xu, G.Q, Mao, S, Mao, L.F, Jiang, Y.Q, Zhang, P, Li, W, Design, synthesis, and antifungal evaluation of novel 1,4-disubstituted 1,2,3-triazoles containing indole framework, Zeitschrift fur Naturforschung Section B-A Journal of Chemical Sciences, 2016, 71, 953-958.

7. da Silva, G.B, Guimaraes, B.M, Assis, S.P.O, Lima, V.L.M, de Oliveira, R.N, Ultrasound-Assisted Synthesis of 1-N-beta-DGlucopyranosyl-1H-1,2,3-triazole Benzo- heterocycles and their Anti-Inflammatory Activities, Journal of Brazilian Chemical Society, 2013, 24, 914-921.

8. Kolb, H.C, Finn, M.G, Sharpless, K.B, Click chemistry: Diverse chemical function from a few good reactions, Angewandte Chemie International Edition, 2001, 40, 2004-2021.

9. Botelho, M.B.S, Fernandez-Hernandez, J.M, de Queiroz T.B, Eckert, H, de Cola, L, de Camargo, A.S.S, Iridium(III)-surfactant complex immobilized in mesoporous silica via templated synthesis: a new route to optical materials, Journal of Material Chemistry, 2011, 21, 8829-8834.

10. Zammit, C.M, Wills, M, Use of triazole-ring formation to attach a $\mathrm{Ru} / \mathrm{TsDPEN}$ complex for asymmetric transfer hydrogenation to a soluble polymer, Tetrahedron: Asymmetry, 2013, 24, 844-852. 
11. Simmons, J.T, Allen, J.R, Morris, D.R, Clark, R.J, Levenson, C.W, Davidson, M.W, Zhu, L., Integrated and Passive 1,2,3-Triazolyl Groups in Fluorescent Indicators for Zinc(II) Ions: Thermodynamic and Kinetic Evaluations, Inorganic Chemistry, 2013, 52, 5838-5850.

12. Mindt, T.L, Struthers, H, Brans, L, Anguelov, T, Schweinsberg, C, Maes, V, Tourwe, D, Schibli, R, "Click to chelate": Synthesis and installation of metal chelates into biomolecules in a single step Journal of American Chemical Society, 2006, 128, 15096-15097.

13. Wang, J.-H, Wolff, M, Eychenne, R, Mallet-Ladeira, S, Benoist, E, Dirhenium(I) hexacarbonyl complexes bridged by 1,2,3-triazole ligand: Synthesis, structural and spectroscopic characterization, Inorganica Chimica Acta, 2017, 466, 551-558.

14. Burley, G.A, Boutadla, Y, Davies, D.L, Singh, K, Triazoles from $\mathrm{N}$-Alkynylheterocycles and their coordination to iridium, Organometallics, 2012, 31, 1112-1117.

15. Kumar, S, Saleem, F, Singh, A.K, 'Click' generated 1,2,3-triazole based organosulfur/selenium ligands and their $\mathrm{Pd}(\mathrm{II})$ and $\mathrm{Ru}(\mathrm{II})$ complexes: their synthesis, structure and catalytic applications, Dalton Transactions, 2016, 45, 11445-11458.

16. Saleem, F, Rao, G.K, Kumar, A, Mukherjee, G, Singh, A.K Catalyst activation with $\mathrm{Cp} \mathrm{p}^{*} \mathrm{Rh}-\mathrm{III} / \mathrm{Ir}-\mathrm{III}-1,2,3$-triazole-based organochalcogen ligand complexes: Transfer hydrogenation via loss of $\mathrm{Cp}^{*}$ and $\mathrm{N}$-methylmorpholine $\mathrm{N}$-oxide based vs oppenauertype oxidation, Organometallics, 2014, 33, 2341-2351.

17. Huang, J, Cai, J, Feng, H, Liu, Z, Fu, X, Miao, Q, Synthesis of salen Mn(III) immobilized onto the ZnPS-PVPA modified by 1,2,3-triazole and their application for asymmetric epoxidation of olefins, Tetrahedron, 2013, 69, 5460-5467.

18. Hua, C, Vuong, K.Q, Bhadbhade, M, Messerle, B.A, New rhodium(I) and iridium(I) complexes containing mixed pyrazolyl1,2,3-triazolyl ligands as catalysts for hydroamination, Organometallics, 2012, 31, 1790-1800.
19. Warsink, S, Drost, R.M, Lutz, M, Spek, A.L, Elsevier, C.J, Modular synthesis of bidentate triazolyl-functionalized $\mathrm{N}$ Heterocyclic carbenes and their palladium complexes, Organometallics, 2010, 29, 3109-3116.

20. Vuong, K.Q, Timerbulatova, M.G, Peterson, M.B, Bhadbhade, M, Messerle, B.A, Cationic Rh and Ir complexes containing bidentate imidazolylidene-1,2,3-triazole donor ligands: synthesis and preliminary catalytic studies, Dalton Transactions, 2013, 42, 14298-14308.

21. Gu, S, Xu, H, Zhang, N, Chen, W, Triazole-Functionalized NHeterocyclic carbene complexes of palladium and platinum and efficient aqueous Suzuki-Miyaura coupling reaction, ChemistryAn Asian Journal, 2010, 5, 1677-1686.

22. Gu, S, Du, J, Huang, J, Xia, H, Yang, L, Xu, W, Lu, C, Bi- and trinuclear copper(I) complexes of 1,2,3-triazole-tethered NHC ligands: synthesis, structure, and catalytic properties, Beilstein Journal of Organic Chemistry, 2016, 12, 863-873.

23. Özdemir, İ, Şahin, N, Gök, Y, Demir, S, Çetinkaya, B, In situ generated 1-alkylbenzimidazole-palladium catalyst for the Suzuki coupling of aryl chlorides, Journal of Molecular Catalysis A:Chemical, 2005, 234, 181-185.

24. Kwok, S.W, Fotsing, J.R, Fraser, R.J, Rodionov, V.O, Fokin, V.V, Transition-Metal-Free catalytic synthesis of 1,5-Diaryl-1,2,3triazoles, Organic Letters, 2010, 12, 4217-4219.

25. Küçükbay, H, Mumcu, A, Tekin, S, Sandal, S, Synthesis and evaluation of novel N,N'-disubstituted benzimidazolium bromides salts as antitumor agents, Turkish Journal of Chemistry, 2016, 40, 393-401.

26. Karataş, M.O, Günal, S, Mansur, A, Alıcı, B, Çetinkaya, E, Synthesis and antimicrobial properties of cycloheptyl substituted benzimidazolium salts and their silver(I) carbene complexes, Heterocyclic Communications, 2016, 22, 357-361. 